\title{
Conhecimento ecológico local de pescadores artesanais do sul da Bahia, Brasil, sobre as interações tróficas de tubarões
}

\author{
Márcio Luiz Vargas Barbosa Filho ${ }^{1 *}$ \\ Eraldo Medeiros Costa Neto ${ }^{2}$

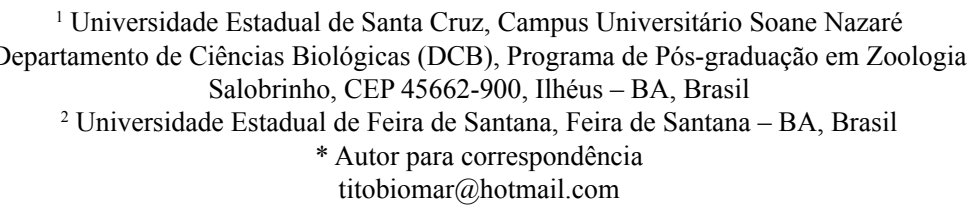

Submetido em 10/11/2015

Aceito para publicação em 27/04/2016

\section{Resumo}

Não obstante as graves ameaças que enfrentam as espécies de tubarões que habitam a Costa Central brasileira, os conhecimentos sobre a história de vida desses animais ainda são bastante escassos. O presente estudo descreve o conhecimento e percepções de pescadores do sul da Bahia, Brasil, sobre interações tróficas de tubarões. O objetivo deste trabalho foi gerar informações científicas que contribuam para um maior entendimento sobre a história de vida das espécies de tubarões existentes nessa pouco conhecida região. Em 2012, realizaram-se entrevistas semiestruturadas com 65 pescadores, com mais de 15 anos de experiência, sobre a pesca e aspectos da alimentação desses peixes. Os participantes detêm conhecimentos etnoecológicos detalhados sobre os comportamentos alimentares dos tubarões, além de terem apontado 39 tipos de itens como componentes da dieta desses animais. Reconhecem também as presas preferenciais de cada etnoespécie de tubarão. Sugere-se o desenvolvimento de pesquisas semelhantes sobre os tubarões ao longo da costa brasileira. Assim, será possível gerar conhecimentos mais detalhados e/ou novas hipóteses científicas sobre as relações interespecíficas desses predadores e também das suas presas.

Palavras-chave: Alimentação; Elasmobrânquios; Etnoecologia; História de vida; Nordeste do Brasil

\section{Abstract}

Local ecological knowledge of artisanal fishermen in southern Bahia, Brazil, about trophic interactions of sharks. Despite the serious threats that affect shark species living along the central coast of Brazil, knowledge about the life history of these animals is still scarce. The present study describes the knowledge and perceptions of fishermen from southern Bahia, Brazil, on the trophic interactions of sharks. The objective of this work was to generate information that contributes to a better understanding of the life history of sharks from this poorly known region. In 2012, semi-structured interviews were conducted with 65 fishermen, with over 15 years of experience, about fisheries and aspects of shark feeding behavior. The study found that the participants have comprehensive ethno-ecological knowledge about shark feeding habits, describing 39 types of items as components of the diets of these animals. They are also able to 
recognize the favored items in the diet of each ethnospecies of shark. Similar studies about shark feeding habits along the Brazilian coast should be developed. This will generate more detailed knowledge and/or new scientific hypotheses about the interspecific relationships of these predators and their prey.

Key words: Elasmobranches; Ethnoecology; Feeding; Life history; Northeastern Brazil

\section{Introdução}

Devido a inúmeras adaptações, desenvolvidas ao longo de mais de quatro centenas de milhões de anos, os tubarões são considerados um dos principais predadores de topo das cadeias alimentares dos ambientes marinhos (MYERS et al., 2007). Consequentemente, exercem efeitos desproporcionais, em relação à sua própria biomassa ou abundância, sobre as comunidades aquáticas. Figuram como elementos imprescindíveis para a estabilidade desses ecossistemas, tanto por controlarem as populações de presas quanto por exercerem uma forte pressão evolutiva ao consumir os animais velhos e doentes (STEVENS et al., 2000; ESTES et al., 2011). Além disso, contribuem diretamente para que nas comunidades marinhas não ocorram cascatas tróficas (FERRETTI et al., 2010; BORNATOWSKI et al., 2014), termo utilizado para designar a propagação dos impactos de determinado nível trófico sobre outros níveis tróficos com os quais não interage diretamente (ESTES et al., 2011). Diante do status de espécieschave nos ambientes marinhos, o desenvolvimento de iniciativas direcionadas ao manejo e conservação dos tubarões torna-se prioritário para a estabilidade desses ecossistemas.

Assim, sob a perspectiva ecossistêmica, um dos aspectos mais relevantes nas relações interespecíficas dos tubarões envolve seus hábitos alimentares. No entanto, dada a inerente dificuldade em se estudar os elasmobrânquios no seu ambiente natural, ainda existe pouco conhecimento acadêmico sobre seus comportamentos de forrageamento (MOTTA; WILGA, 2001). Motta e Wilga (2001) salientam ainda que grande parte de tais conhecimentos advém de observações anedóticas. Por exemplo, nos últimos anos, pescadores têm reportado aos cientistas inúmeras agregações alimentares sazonais de tubarões-baleia (Rhincodon typus Smith, 1828) ao redor do mundo (DE LA PARRA VENEGAS et al., 2011; HEYMAN et al., 2001;
JONAHSON; HARDING, 2007; STACEY et al., 2012). Pelo fato de $75 \%$ das 1.041 espécies de elasmobrânquios estarem alocadas atualmente em algum status de ameaça segundo a IUCN (DULVY et al., 2014), a aplicação de técnicas não letais tem figurado como um requisito cada vez mais valorizado em estudos sobre a história de vida desses animais (HEUPEL; SIMPFENDORFER, 2010; SIMPFENDORFER; WETHERBEE, 2015).

Aguiar e Valentin (2010), em uma revisão a respeito do conhecimento científico sobre biologia e ecologia alimentar de elasmobrânquios no Brasil, relataram que somente $26 \%$ do total da riqueza das espécies registradas no país já tiveram sua biologia alimentar estudada, sendo tais estudos geralmente dirigidos a suprir a carência do conhecimento, sem, no entanto, apresentarem preocupações com ações de manejo direcionadas a esses predadores e suas presas. Também apontam para a existência de grandes lacunas nesse campo de conhecimento e, por isso, recomendam fortemente o desenvolvimento de pesquisas científicas e proposições para a gestão das populações estudadas. Diante desse contexto e pelo fato de os conhecimentos relativos às espécies de tubarões na área de estudo serem raros (NUNAN; SENNA, 2007), pesquisas que visem a descrever tais interações ecológicas se tornam altamente relevantes e podem subsidiar ações com vistas à conservação das populações locais desses peixes.

Os conhecimentos etnoecológicos de pescadores artesanais podem contribuir diretamente para a melhor compreensão da biologia e ecologia de espécies aquáticas, além de embasar o desenvolvimento de novas hipóteses científicas (JOHANNES et al., 2000). Em relação aos estudos sobre a história de vida dos tubarões, a aplicação de métodos e técnicas da Etnoecologia apresentam diversas vantagens, como o baixo custo financeiro e, principalmente, o fato de geralmente se utilizarem de técnicas não letais. Também existem informações que, como Marques (1991) aponta, dificilmente poderiam ser 
acessadas pela aplicação de outros métodos científicos, dada a raridade com que ocorrem. Por exemplo, em seu estudo, por meio da análise do conteúdo estomacal de bagres (Arius helzberg Bloch, 1794), Marques (1991) confirmou a hipótese implausível, desenvolvida com base em informações transmitidas pelos pescadores de Alagoas, Brasil, de que esses peixes alimentavam-se de insetos terrestres (Ephemeroptera). Tal informação ainda não havia sido registrada na literatura científica. No município de Canavieiras, na área do presente estudo, Costa et al. (2012) confirmaram um comportamento alimentar peculiar, ainda não descrito na literatura científica, do golfinho Sotalia guianensis (Van Beneden, 1864). Nos rios locais, tais cetáceos geralmente batem a nadadeira caudal contra as raízes do mangue para dispersar as presas escondidas, comportamento previamente relatado apenas pelos pescadores locais.

Diante desse cenário, o presente estudo visou a descrever os conhecimentos e percepções de pescadores artesanais da Costa Central brasileira sobre as interações tróficas exibidas pelos tubarões. Também, este trabalho objetivou gerar informações científicas que contribuam para um maior entendimento sobre a ecologia das espécies envolvidas nestas interações.

\section{Material e Métodos}

\section{Área de estudo}

A região costeira da Bahia compreende o limite sul das formações de recifes de coral no Atlântico Sudoeste (DUTRA et al., 2006) e, por possuir uma plataforma continental estreita, propicia o desenvolvimento da pesca de linha de mão e da pesca com espinhel para a captura de peixes recifais, tubarões e atuns nas zonas do início do talude oceânico (VASCONCELLOS et al., 2011). Em sentido norte-sul, a área de estudo compreende as cidades de Ilhéus, Una e Canavieiras. Dentre os municípios do litoral sul do estado, o Porto de Malhado e o Pontal, no município de Ilhéus, e o Porto Grande, no município de Canavieiras, destacam-se em termos de produção pesqueira (IBAMA, 2008). Existem duas colônias de pescadores em Ilhéus: a Z-19 e a Z-34. Segundo Braga e Schiavetti (2013), a Z-19, que se localiza na extremidade da Baía do Pontal, é composta por 3.000 membros, dos quais apenas 700 são pescadores ativos. Já a Colônia Z-34, localizada no bairro do Malhado, tem cerca de 3.000 membros ativos. Cavalcante (2011) revela que na cidade de Canavieiras mais de $70 \%$ dos pescadores encontram-se vinculados à Colônia de Pescadores Z-20, que se localiza no centro da cidade e conta com cerca de mil associados.

Regionalmente, linhas de mãos, redes de espera, tarrafas e espinhéis são as principais artes empregadas na pesca (BARBOSA-FILHO et al., 2014) e, não obstante a multiespecificidade dessas pescarias, os recursos ícticos com maiores volumes de desembarques pertencem aos gêneros Epinephelus, Lutjanus e Scomberomorus, além de espécies como a guaiúba (Ocyurus chrysurus Bloch, 1791), o olho-de-boi (Seriola dumerili Risso, 1810), o dourado (Coryphaena hippurus Linnaeus, 1758), além de robalos (Centropomus sp.) (CETRA; PRETERE, 2014; ERLER et al., 2015). Ainda não existem informações científicas a respeito das espécies de tubarões que costumam ser capturadas pelos pescadores locais.

A única lista das espécies de tubarões do litoral da Bahia foi elaborada por Queiróz e Rebouças (1995) e apresenta 26 espécies. São elas: Rhizoprionodon porosus (Poey, 1861); Rhizoprionodon lalandii (Valenciennes, 1839); Carcharhinus falciformis (Bibron, 1841); Carcharinus limbatus (Valenciennes, 1841); Carcharhinus maou (Poey, 1861); Carcharhinus obscurus (Lesueur, 1818); Carcharhinus acronotus (Poey, 1861); Carcharhinus brevipinna (Muller \& Henle, 1839); Carcharhinus plumbeus (Nardo, 1827); Carcharhinus leucas (Müller \& Henle, 1839); Carcharhinus perezi (Poey, 1876); Prionace glauca (Linnaeus, 1758); Galeocerdo cuvier (Péron \& Lesueur, 1822); Ginglymostoma cirratum (Bonnaterre, 1788); Mustelus higmani (Springer \& Lowe, 1963); Scyliorhinus haeckeli (Ribeiro, 1907); Alopias vulpinus (Bonnaterre, 1788); Alopias superciliosus (Lowe, 1840); Negaprion brevitostris (Poey, 1868); Isistius brasiliensis (Quoy \& Gaimard, 1824); Rhincodon typus; Sphyrna tudes (Valenciennes, 1822); Sphyrna mokarran (Ruppel, 1837); Sphyrna media (Springer, 1940); Sphyrna lewini (Griffith \& Smith, 1834) e Sphyrna tiburo (Linnaeus, 1758). Nos últimos anos, por meio de prospecções 
pesqueiras oceanográficas realizadas pelo Programa de Avaliação Sustentável de Recursos Vivos na Zona Econômica Exclusiva (REVIZEE) (OLAVO et al., 2005; NUNAN; SENNA, 2007), mais dez espécies foram descobertas no litoral da Bahia. São elas: Carcharhinus signatus (Poey, 1868); Isurus oxyrinchus (Rafinesque, 1810); Isurus paucus (Guitart, 1966); Sphyrna zygaena (Linnaeus, 1758); Squalus cubensis (Howell Rivero, 1936); Heptranchias perlo (Bonnaterre, 1788); Etmopterus bigelowi (Shirai \& Tachikawa, 1993); Etmopterus gracilispinis (Krefft, 1968); Centroscymnus coelolepis (Bocage \& Capello, 1864) e Squatina dumeril (Lesueur, 1818).

\section{Coleta e análise dos dados}

Antes de se iniciar a coleta de informações junto aos pescadores, foi protocolada uma requisição junto ao Comitê de Ética em Pesquisas com Seres Humanos da Universidade Estadual de Santa Cruz, por meio do site da Plataforma Brasil. O pedido foi aprovado sob o no ${ }^{0} 25.275$. Uma proposta de pesquisa também foi cadastrada no Sistema de Autorização e Informação em Biodiversidade
(SISBIO), uma exigência do Instituto Brasileiro do Meio Ambiente e dos Recursos Naturais Renováveis (IBAMA) para a realização de estudos científicos que abordem o conhecimento tradicional de beneficiários de Unidades de Conservação (UC) Federais. Nesse órgão, o protocolo de liberação da pesquisa tem o $n^{-}$33.276-1 e foi concedido especificamente para a realização de entrevistas com os beneficiários da Reserva Extrativista de Canavieiras. Ressalta-se também que os contatos com os pescadores seguiram recomendações técnicas e éticas sugeridas por Bunce et al. (2000), no intuito de esclarecer os participantes sobre os benefícios e possíveis desconfortos concernentes à presente pesquisa, além de minimizar as alterações na rotina desses atores sociais.

Durante os meses de março a outubro de 2012, foram realizadas entrevistas, por meio de um formulário semiestruturado, com 65 pescadores do sexo masculino de 14 comunidades (Figura 1) das cidades de Canavieiras, Una e Ilhéus, no litoral sul da Bahia.

A escolha dos entrevistados ocorreu por meio de uma rede de especialistas (MARQUES, 2001) com mais de 15 anos na captura de tubarões. Além de questões

FIGURA 1: Localização geográfica das comunidades onde as entrevistas foram realizadas.

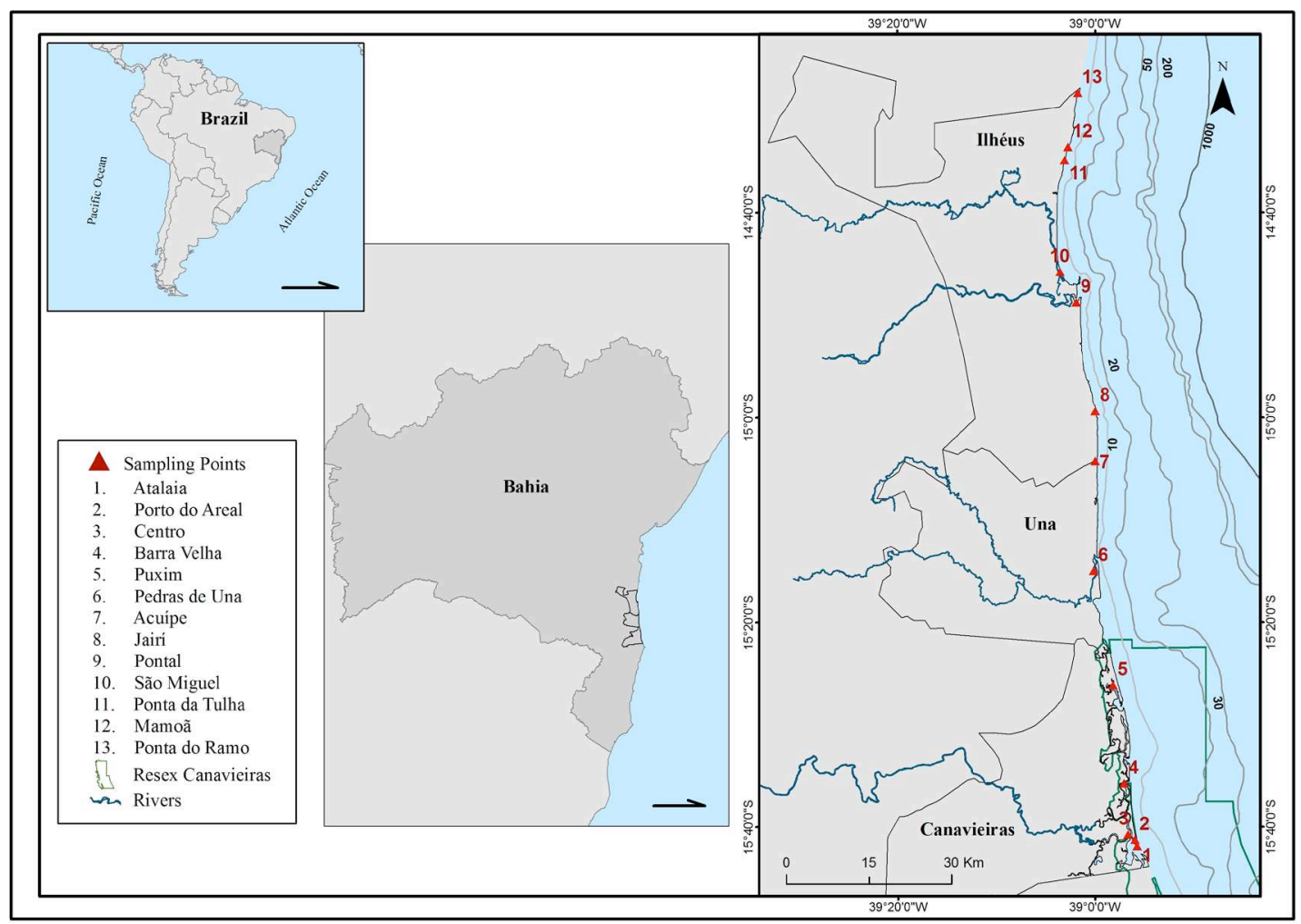


gerais sobre a pesca de tubarões, o formulário continha perguntas sobre os conhecimentos e percepções dos pescadores sobre as interações alimentares verificadas por eles. Por meio da utilização de um gravador de áudio digital, as entrevistas foram registradas e o tempo total das gravações foi de 70h40min, com tempo médio de entrevista de $1 \mathrm{~h} 05 \mathrm{~min}$ com cada participante.

Para análise dos dados foi utilizada uma abordagem qualitativa por meio do modelo da união de diversas competências individuais, técnica amplamente aplicada em estudos etnobiológicos, em que todas as informações compartilhadas pelos informantes são consideradas (MARQUES, 1991).

\section{Resultados}

\section{Tubarões como predadores}

Regionalmente, a nomenclatura "cação" é atribuída a todas as espécies de tubarões com as quais os pescadores interagem. Segundo estes, as principais etnoespécies capturadas foram: cação panã (100\%; $\mathrm{n}=65)$, cação bico-doce $(93,8 \% ; \mathrm{n}=61)$, cação-gata $(87,7 \% ; n=57)$, cação-galha-preta $(\% ; n=45)$, cação lixa $(69,2 \% ; n=45)$, cação viola $(55,4 \% ; n=36)$, cação alvacora $(43,1 \% ; n=28)$ e cação sucurupoia $(29,2 \% ; n=19)$.

Por reconhecerem os padrões comportamentais exibidos pelos tubarões, os pescadores adotam medidas que contribuem para um maior sucesso nas capturas, como a escolha do material e isca adequados. Fazem isso também para uma maior segurança à prática pesqueira. Por exemplo, existem aqueles que evitam entrar na água em mar aberto.

Geralmente, logo que questionados, os pescadores relatam que "os tubarões comem tudo". No entanto, quando se pediu aos entrevistados que detalhassem sobre os itens alimentares dos tubarões, eles demonstraram um conhecimento apurado e, frequentemente, condizente com a literatura científica. Assim, foi possível observar a citação de 39 itens alimentares como componentes da dieta desses animais. A frequência de citações de parte deles encontra-se na Tabela 1. Cada um dos itens "casca de coco", "boia", "sapato", "papelão", "lona", "garrafa pet", "vidro", "cachorro", "penico", "búzio" e "carneiro" foi citado por apenas um entrevistado.

TABELA 1: Itens alimentares que compõem a dieta dos tubarões, na percepção dos pescadores $(n=65)$.

\begin{tabular}{ccc}
\hline Item Alimentar & $\begin{array}{c}\text { Frequência } \\
\text { Absoluta (n) }\end{array}$ & $\begin{array}{c}\text { Frequência } \\
\text { Relativa (\%) }\end{array}$ \\
\hline Peixe & 61 & 93,8 \\
Camarão & 26 & 40 \\
Lagosta & 24 & 36,9 \\
Tartaruga & 23 & 35,4 \\
Gaivota & 18 & 27,7 \\
Plástico & 17 & 26,1 \\
Lula & 14 & 21,5 \\
Pato-do-mar & 14 & 21,5 \\
Golfinho & 13 & 20 \\
Toninha & 11 & 16,9 \\
Polvo & 11 & 16,9 \\
Baleia & 10 & 15,4 \\
Lata & 10 & 15,4 \\
Tatu & 8 & 12,3 \\
Albatroz & 7 & 10,8 \\
Boi & 7 & 10,8 \\
Madeira & 7 & 10,8 \\
Marisco & 6 & 9,2 \\
Siri & 6 & 9,2 \\
Caranguejo & 5 & 7,7 \\
Saco de lixo & 5 & 7,7 \\
Isopor & 4 & 6,1 \\
Gente & 4 & 6,1 \\
Carniça & 3 & 4,6 \\
Pinguim & 3 & 4,6 \\
Galo & 2 & 3,1 \\
Arame & 2 & 3,1 \\
Placa de carro & 2 & 3,1 \\
\hline & &
\end{tabular}

Nos depoimentos, notou-se a predominância da citação do item alimentar "peixe". Essa preferência é salientada com argumentos como: "o cação corta todo tipo de peixe" ou "é mais pêxe que os cação gosta". Ataques oportunistas aos peixes fisgados são constantemente descritos, comportamento mencionado como "roubar o peixe da linha". Observa-se que os ataques oportunistas dos tubarões aos peixes fisgados desencadeiam um contra-ataque (também oportunista) por parte dos pescadores. Nessas ocasiões, imediatamente, estes costumam lançar linhas e iscas adequadas no intuito de capturar o animal: 
[...] o minino ferrou um badejo, o cação veio e cortô. Ai na mesma hora nois pegamo uma linha 250 (mm), botamo no anzol aí, importado no aço, iscamo um pedaço do badejo que já tava cortado, num demorô ele pegou: taaaa! Trabalhamo, matamo! (C., 64 anos).

O item "camarão" foi apontado como componente da dieta dos tubarões por $40 \%$ dos pescadores. Regionalmente, existe um segmento da frota pesqueira das três cidades da área de estudo que direciona seu esforço de pesca à captura de camarões com redes de arrasto, denominada localmente de "arrastão". Os participantes também alegam que embarcações de grande porte provenientes de outras cidades e até mesmo de outros estados costumam vir capturar camarões com embarcações do tipo "guincho" e reclamam que esse tipo de pesca os atrapalha de diversas maneiras. Por exemplo, alegam que os guinchos de fora desperdiçam grandes quantidades de peixes ainda pequenos e chegam até a roubar as redes dos pescadores nativos. Também reclamam que o "arrastão" está afastando (= "iscurraçando" ou "ispantando") os tubarões da região, principalmente pela diminuição da oferta de alimento a esses peixes. Tal percepção fica mais evidente no discurso dos pescadores quando estes se utilizam de termos que denotam a expulsão dos tubarões da região, como verificado nos seguintes trechos:

O cação foi iscurraçado da área pelo arrastão (E., 62 anos).

$O$ arrasto ispanta o cação (C., 55 anos).

A pescaria de arrasto de camarão foi o que acabou com essa pesca nossa aqui. Porque eles pesca todos tipo de pêxes, camarão. Se num existe a frequença do pêxe miúdo na costêra, num existe a frequença do camarão, intão qué dizê o quê? Intão os outro pêxe se afasta da praia. Tem impacto e grande! (C., 64 anos).

Desse modo, a diminuição apontada nos rendimentos das capturas regionais de tubarões é justificada por mais da metade dos entrevistados $(62,7 \%)$ pela atuação dos "arrastões". Além de reportarem o impacto direto sobre as populações dos camarões capturados, esses pescadores salientam que as redes capturam grande quantidade de filhotes de espécies de peixes de médio e grande porte, "caranguejos do mar", "siris" e outros tipos de "mariscos" que servem como presas para os tubarões. Quebram e arrancam até mesmo "pedaços de corais".

Outros crustáceos como os genéricos "lagosta", "marisco", "siri" e "caranguejo" também foram citados pelos participantes como alimentos dos tubarões. O cação-lixa ( $G$. cirratum) foi a principal etnoespécie apontada como predadora de tais recursos. Um dos participantes afirmou já ter verificado a etnoespécie cação-estrela ( $R$. typus) se alimentando de "uns camarãozinho", aos quais denominou de "krill", como verificado no trecho de depoimento abaixo:

Ele (o cação-estrela) passava a cara no barco toda hora, acho que catando aqueles camarãozinho que ele come, acho que é krill, né? (R., 36 anos).

Tartarugas foram apontadas como item alimentar dos tubarões por um terço dos pescadores. Aves marinhas também foram citadas como alimento dos tubarões, principalmente no inverno. São elas: "gaivota" (27,7\%; $\mathrm{n}=18)$, "pato-do-mar" $(21,5 \% ; \mathrm{n}=14)$, "albatroz" $(10,8 \% ; \mathrm{n}=7)$ e "pinguim" $(4,6 \% ; \mathrm{n}=3)$. Os pescadores já encontraram aves no trato digestivo de G. cuvier, além de terem avistado ataques da espécie quando as aves estão "pousadas na água". Em determinadas épocas do ano é comum o aparecimento de pinguins nas praias da área de estudo, inclusive de animais vivos. Assim, três participantes relataram o consumo de pinguins pelo cação-gata (Galeocerdo cuvier), alegando já terem capturado indivíduos com essas aves no estômago. Além disso, alguns pescadores relataram já ter encontrado pinguins vivos no mar local e, até mesmo, levado exemplares para a terra no intuito de salvá-los.

Os cetáceos também foram apontados pelos pescadores como componentes da dieta de tubarões. Assim, apontam que esses animais são tanto atacados vivos quanto mordidos depois de mortos. De fato, na região é possível verificar a chegada de grandes e pequenos cetáceos mortos nas praias com mordidas de tubarões, como a carcaça do exemplar de golfinhonariz-de-garrafa (Tursiops trunctatus Montagu, 1821), encalhada na Praia do Patizeiro, Itacaré - BA no ano de 2011. No entanto, para esse indivíduo, não foi possível reconhecer a espécie de tubarão que realizou a mordida e nem se o animal estava vivo ou morto quando foi mordido. 
Quanto aos cetáceos de grande porte, o genérico "baleia" foi o único relatado. De acordo com dois participantes, na "época das baleia", tubarões de grande porte costumam seguir esses animais para se alimentarem. Assim, apontam tanto o consumo de baleias jubarte mortas quanto cicatrizes de mordidas de tubarões em exemplares de jubarte vivas:

Chega na época das baleia passá [...] aí eles (os tubarões) vão atrás da baleia, meu amigo. E quando diz assim: 'Uma baleia morreu em tal canto.' Pode ir por fora que eles tão por ali esperando (A., 58 anos).

A época que dá mais tubarão é na época da baleia... Ele tira um pedaço da baleia e depois cicatriza. E a baleia quando ela vem, ela solta o engodo e a placenta, quando ela pare [...] E o tubarão é carnívoro, corta tudo. E a baleia é toda bocada, ela. Você já viu uma baleia toda bocada de cação? Ele tira um pedaço e aquilo pra baleia num é nada, cicatriza. Pode acreditá que é(V., 37 anos).

Além de cetáceos, os participantes ressaltam que os tubarões-tigre (G. cuvier) também se alimentam de outros animais mortos, denominados regionalmente como "carniça". Por vezes, são os animais terrestres os consumidos na forma de "carniça". De acordo com os participantes, o aparecimento desses animais no mar se deve às cheias dos rios durante tempestades, as quais formam enxurradas e carreiam alguns animais, principalmente de fazendas cujos limites se localizam na beira dos rios. Os principais citados foram: o boi (Bos taurus Linnaeus, 1758), citado por sete (10,8\%) participantes, e o galo (Gallus gallus domesticus Linnaeus, 1758), citado por apenas dois $(3,1 \%)$.

Já os itens inorgânicos citados correspondem a alguns objetos de uso humano, que chegam ao mar na forma de lixo, sejam eles carreados pelos rios locais, descartados na praia ou diretamente no mar por embarcações. Nesse sentido, alguns pescadores apontam para o comportamento de "seguir os barcos para comerem o lixo", que é apresentado por algumas etnoespécies de tubarões, incluindo G. cuvier. A alta variedade de itens alimentares constatados, pelos pescadores ao "disbuchar" (= "tirar o bucho" = eviscerar) tubarões-tigre, culmina para que essa espécie seja considerada "um cação que come todo tipo de porcaria".

\section{Tubarões como presas}

Verificou-se que 55,4\% $(\mathrm{n}=36)$ dos entrevistados acreditam que tubarões também são consumidos, sendo que a metade deles relatou que apenas tubarões conseguem predar tubarões, inclusive dentro de uma mesma espécie. Desse modo, uma expressão frequente $(50,8 \%, \mathrm{n}=33)$ nas entrevistas é a de que "Só quem pode com o cação é ele mesmo e Deus!". É digno de nota o fato de que dois pescadores apontaram os seres humanos como animais predadores dos tubarões, um indício de que estes se reconhecem como mais um elo componente das teias tróficas marinhas.

\section{Discussão}

Não raro, por meio do detalhamento feito pelos pescadores em relação às características das principais etnoespécies capturadas, é possível identificar a espécie em questão. Por exemplo, os pescadores afirmam que o cação-gata come qualquer coisa, frequenta a beira das praias, tem manchas escuras na lateral do corpo e cresce muito. Tais pistas taxonômicas permitem afirmar que se trate de G. cuvier, espécie que, de fato, apresenta tais características (SZPILMAN, 2004). Possivelmente, todos os pescadores citaram o cação-panã por conta da existência de ao menos seis espécies do gênero Sphyrna no litoral da Bahia (QUEIROZ; REBOUÇAS, 1995; OLAVO et al., 2005). De fato, Gadig (1994) aponta que o epíteto "panã" é empregado pelos pescadores do Nordeste do Brasil para designar diversas espécies desse gênero.

Os pescadores entrevistados também demonstraram possuir conhecimentos detalhados sobre diversos aspectos ecológicos relacionados à alimentação dos tubarões. Tais saberes viabilizam a adoção de pescarias mais seguras e rentáveis, pela escolha das iscas adequadas nas ocasiões em que optam pela captura desses peixes. Sob a perspectiva da Ecologia Evolutiva, a atitude de alguns participantes de não entrar na água em mar aberto pode ser enquadrada como um tipo de predação sensível ao risco (RICKLEFS, 2003), na qual mesmo o bem-estar ocasionado por entrar na água do mar não é suficiente para que estes se sujeitem à possibilidade de sofrerem ataques. 
O argumento de que os tubarões "comem tudo", possivelmente, está atrelado à histórica crença que permeia o imaginário coletivo humano que atribui a esses peixes a imagem de animais ameaçadores e insaciáveis, que se alimentam do que for possível (MAGNUSON, 1987). Sendo assim, não é por acaso que alguns participantes citaram os seres humanos como item alimentar dos tubarões. Além disso, o fato de a região ser uma área de vida do tubarão-tigre (G. cuvier), espécie de grande porte e que apresenta comportamento oportunista e hábitos alimentares pouco seletivos (LOWE et al., 1996), contribui para a crença local de que todas as espécies de tubarões apresentam características semelhantes. BarbosaFilho et al. (2014) já haviam apontado que G. cuvier é a espécie de elasmobrânquio culturalmente comum na área de estudo, justamente por conta dos seus comportamentos e hábitos alimentares.

Estudos têm demonstrado que os tubarões são predadores oportunistas assincrônicos, sendo que a dieta da maior parte das espécies se baseia no consumo de peixes (BRES, 1993; MOTTA; WILGA, 2001; WILGA et al., 2007). O "roubo do peixe", que segundo os pescadores lhes causa prejuízo, não parece desencadear antipatia nestes em relação aos tubarões. Talvez esse fato esteja relacionado à prática dos pescadores de capturar os tubarões que atacam os peixes fisgados. Ainda em relação ao "roubo dos peixes", os pescadores, invariavelmente, salientam que os tubarões encontram-se no seu ambiente natural ("em sua área") e que só atacam os peixes fisgados por "sentirem os peixes se debatendo na linha”. Os entrevistados conseguem reconhecer as propriedades sensoriais relacionadas à capacidade de detecção de campos elétricos pelos tubarões. Esse fato fica mais evidente quando eles dizem que "os cações reconhece a comida pela batida do coração" e que em casos de situações de risco de ataques "se a pessoa ficar parada na água o cação não mexe com ela".

Segundo Marques (1991), o hábitat trófico utilizado pelos tubarões para o consumo de camarões é a lama. Os entrevistados apontam que os tubarões estão sendo afastados do litoral pelas redes de arrasto. Ainda de acordo com estes, pelo fato de a pesca de arrasto estar acabando com a comida dos tubarões nas zonas costeiras, nos últimos anos, esses peixes estão deixando de vir para a beira, preferindo ficar nas áreas mais profundas onde ainda existe alimento. Para a área estudada, diversos trabalhos têm apontado o impacto negativo da pesca de arrasto de camarão sobre a própria pesca, o assoalho marinho e também sobre diversos grupos animais (ALARCON; SCHIAVETTI, 2005; DÂMASO, 2006; VASQUES, 2006; BURDA, 2007; ALARCON et al., 2009; MORAES et al., 2009; BRAGA; SCHIAVETTI, 2013). No entanto, para a área de estudo, este é o primeiro relato de impacto da pesca de arrasto de camarões para as populações locais de tubarões.

Diversos tipos de crustáceos e moluscos bivalves são relatados pela literatura científica como um dos principais componentes da dieta do tubarão-lixa ( $G$. cirratum) (FIGUEIREDO, 1977; COMPAGNO, 2001). Em relação aos tubarões-baleia ( $R$. typus), organismos zooplanctônicos destacam-se como um dos principais componentes da dieta desses peixes (DOVE, 2015). Nesse sentido, uma vez que até o presente momento não existem registros científicos da alimentação da espécie para a Bahia, o depoimento de um pescador, que relatou já ter visto um exemplar da espécie comendo plâncton, figura como o primeiro indício da atividade alimentar dessa espécie no estado. Também se ressalta a necessidade de estudos que abordem a ecologia da espécie para essa porção do Oceano Atlântico.

A área de estudo apresenta-se como uma área de alimentação e nidificação dos quelônios Caretta caretta (Linnaeus, 1758), Eretmochelys imbricata (Linnaeus, 1766) e Chelonia mydas (Linnaeus, 1758) (CAMILLO et al., 2009), espécies que se encontram atualmente alocadas na Lista Vermelha de Espécies Ameaçadas do IBAMA nas categorias "em perigo", "criticamente em perigo" e "vulnerável”, respectivamente (MACHADO et al., 2008). Mundialmente, diversos estudos citam o consumo de tartarugas-marinhas por tubarões (FIGUEIREDO, 1977; LOWE et al., 1996; HEITHAUS et al., 2002) e sabe-se que, potencialmente, esse tipo de interação com tubarões pode influenciar a distribuição espacial e o tamanho de populações de tartarugas marinhas (HEITHAUS et al., 2008). Esses autores salientam ainda que referenciais históricos sobre o tamanho de populações de tartarugas e planos de conservação devem levar em conta esses 
fatos. No Brasil, estudos que enfoquem a predação de tartarugas por espécies de grandes tubarões ainda são extremamente raros, ainda que as tartarugas pareçam ser um importante item alimentar para tais animais no Nordeste do Brasil (BORNATOWSKI et al., 2012a). Pelo fato de os pescadores locais apontarem que as tartarugas são frequentemente consumidas por tubarões, apresenta-se como uma demanda científica se determinar a frequência relativa desse consumo e quais as espécies estão envolvidas em tais interações.

Alarcon et al. (2009) relatam que os pescadores de Itacaré reconhecem que aves marinhas das famílias Sulidae e Procellariidae aparecem no inverno e são reconhecidas como "patas grandes" e "patinhas", respectivamente. Esses autores argumentam que a abundância de aves marinhas no litoral da região é influenciada pelo descarte da fauna acompanhante, chamada de "engodo", por embarcações de arrasto de camarão. De fato, estudos têm reportado a predação de aves por G. cuvier (HEITHAUS, 2001; AGUIAR; VALENTIN, 2010) e, de acordo com Lowe et al. (1996), o consumo de aves restringe-se a tubarões de maior porte. $\mathrm{O}$ depoimento dos pescadores figura como o primeiro registro do consumo de aves marinhas por tubarões nesse ponto do litoral brasileiro. Contudo, é necessário determinar quais espécies têm sido consumidas, a frequência e se existe sazonalidade nesse tipo de interação no sul da Bahia.

No inverno austral, o pinguim-de-Magalhães (Spheniscus magellanicus Forster, 1781) costuma migrar da Argentina para as áreas de alimentação no sul do Brasil (MÄDER et al., 2010). Todavia, a força da Corrente das Malvinas no Atlântico Sul costuma carregar anualmente espécimes jovens para as regiões tropicais da costa brasileira (FRERE et al., 1996). Ainda não existem registros na literatura científica do consumo de $S$. magellanicus por G. cuvier em águas brasileiras. Assim, os depoimentos dos pescadores figuram como o único registro dessa plausível interação ecológica, dado que, na Ilha Dyer, África do Sul, o pinguimafricano (Spheniscus demersus Linnaeus, 1758), espécie congênere de $S$. magellanicus, é um componente da dieta de tubarões-brancos (Carcharodon carcharias Linnaeus, 1758) (JOHNSON et al., 2006).
Cockcroft et al. (1989), em um estudo no sul da África, registraram que em $50 \%$ dos exemplares de G. cuvier capturados havia a presença de T. trunctatus em seus tratos digestivos. Acevedo-Gutiérrez (2002), por sua vez, observou um comportamento alimentar sensível ao risco, em que a ingestão dessa espécie de cetáceo por G. cuvier diminuia à medida que se aumentava o número de exemplares de tubarões-lombopreto (Carcharhinus falciformis Müller \& Henle, 1839) no hábitat compartilhado. Além do fato de que nas entrevistas não houve um aprofundamento sobre quais etnoespécies são consumidas por tubarões, a grande diversidade de cetáceos que ocorre na região sul da Bahia (BATISTA et al., 2012) dificulta o reconhecimento de quais espécies científicas estão envolvidas em tais interações ecológicas. Assim, para a região, apresenta-se como uma demanda científica a realização de pesquisas cujo foco seja o conhecimento ecológico dos pescadores a respeito de tal temática.

A baleia jubarte (Megaptera novaeangliae Borowski, 1781) é uma espécie que, entre os meses de julho e novembro, utiliza o litoral da Bahia como área de reprodução (ZERBINI et al., 2004). Assim como os participantes do presente estudo, pescadores da cidade de Caravelas, extremo sul da Bahia, também relatam que tubarões seguem as baleias jubarte no período de migração dessa espécie (BORNATOWSKI et al., 2012b). Bornatowski et al. (2012b) ainda revelam que, apesar do pouco conhecimento sobre o padrão de alimentação de grandes tubarões para a costa brasileira, as espécies $G$. cuvier e C. leucas são potenciais predadoras de baleias-jubarte. Pela análise de carcaças de baleias jubarte e também por meio de fotografias, Bornatowski et al. (2012b) observaram tanto o consumo de baleias jubarte mortas quanto cicatrizes de mordidas de tubarões em exemplares de jubarte vivas, fato que corrobora os depoimentos dos entrevistados.

A partir dos resultados foi possível concluir que a possibilidade de observar em detalhes o ambiente marinho (e as interações ecológicas que aí ocorrem) torna os pescadores artesanais excelentes conhecedores da fauna marinha. Nesse sentido, os pescadores da região sul da Bahia demonstraram ter conhecimentos detalhados sobre variados itens e interações alimentares dos 
tubarões. Em um contexto regional, tais conhecimentos empíricos devem ser aproveitados na formulação de hipóteses científicas que gerem novos e mais detalhados conhecimentos sobre a história de vida desses predadores e de suas presas. Tal fato ganha maior relevância quando se considera que a Costa Central brasileira apresenta-se como um dos principais hotspots mundiais em diversidade de espécies de elasmobrânquios (LUCIFORA et al., 2011) e que, infelizmente, ainda existe pouco conhecimento científico sobre as espécies que habitam essa porção do litoral brasileiro.

\section{Agradecimentos}

A todos os pescadores entrevistados. Albert Levya por ter feito, gentilmente, a revisão do inglês.

\section{Referências}

ACEVEDO-GUTIERREZ, A. Interactions between marine predators: dolphin food intake is related to number of sharks. Marine Ecology Progress Series, Oldendorf, v. 240, p. 267-271, 2002.

AGUIAR, A. A.; VALENTIN, J. L. Biologia e ecologia alimentar de elasmobrânquios (Chondrichthyes: Elasmobranchii): uma revisão dos métodos e do estado da arte no Brasil. Oecologia Australis, Rio de Janeiro, v. 14, n. 2, p. 464-489, 2010.

ALARCON, D. T.; DÂMASO, R. C. S. C.; SCHIAVETTI, A. Abordagem etnoecológica da pesca e captura de espécies não-alvo em Itacaré, Bahia (Brasil). Boletim do Instituto de Pesca (Online), São Paulo, v. 35, n. 4, p. 675-686, 2009.

ALARCON, D. T.; SCHIAVETTI, A. O conhecimento dos pescadores artesanais de Itacaré sobre a fauna de vertebrados (não peixes) associados às atividades pesqueiras. Revista da Gestão Costeira Integrada, Itajaí, v. 4, p. 1-4, 2005.

BARBOSA-FILHO, M. L. V.; SCHIAVETTI, A.; ALARCON, D. T.; COSTA-NETO, E. M. "Shark is the man!": ethno knowledge of Brazil's South Bahia fishermen regarding shark behaviors. Journal of Ethnobiology and Ethnomedicine, London, v. 10, n. 54, 2014. BATISTA, R. L. G.; SCHIAVETTI, A.; SANTOS, U. A.; REIS, M. S. S. Cetaceans registered on the coast of Ilhéus (Bahia), northeastern Brazil. Biota Neotropica, Campinas, v. 12, n. 1, p. 31-38, 2012.

BORNATOWSKI, H.; HEITHAUS, M. R.; BATISTA, C. M. P.; MASCARENHAS, R. Shark scavenging and predation on sea turtles in northeastern Brazil. Amphibia-Reptilia, Leiden, v. 33, n. 3-4, p. 495-502, 2012a.

BORNATOWSKI, H.; NAVIA, A. F.; BRAGA, R. R.; ABILHOA, V.; CORRÊA, M. F. M. Ecological importance of sharks and rays in a structural foodweb analysis in southern Brazil. ICES Journal of Marine Science, Copenhagen, v. 71, n. 7, p. 1586-1592, 2014.
BORNATOWSKI, H.; WEDEKIN, L. L.; HEITHAUS, M. R.; MARCONDES, M. C. C.; ROSSI-SANTOS, M. R. Shark scavenging and predation on cetaceans at Abrolhos Bank, eastern Brazil. Journal of the Marine Biological Association of the United Kingdom, Cambridge, v. 92, n. 8, p. 1767-1772, 2012 b.

BRAGA, H.; SCHIAVETTI, A. Attitudes and local ecological knowledge of experts fishermen in relation to conservation and bycatch of sea turtles (Reptilia: Testudines), Southern Bahia, Brazil. Journal of Ethnobiology and Ethnomedicine, London, v. 9, p. 15, 2013.

BRES, M. The behaviour of sharks. Reviews in Fish Biology and Fisheries, Washington, v. 3, p. 133-159, 1993.

BUNCE, L.; TOWNSLEY, P.; POMEROY, R.; POLLNAC, R. Socioeconomic manual for coral reef management. Townsville: Australian Institute of Marine Science, 2000. 253 p.

BURDA, C. L. Análise ecológica da pesca artesanal e consumo de pescado por quatro comunidades pesqueiras da costa de Itacaré (BA). 2007. 109 f. Dissertação (Mestrado em SistemasAquáticos Tropicais) - Universidade Estadual de Santa Cruz, Ilhéus. 2007.

CAMILLO, C. S., ROMERO, R. M., LEONE, L. G., BATISTA, R. L. G., VELOZO, R. S.; NOGUEIRA-FILHO, S. L. G. Características da reprodução de tartarugas marinhas (Testudines, Cheloniidae) no litoral sul da Bahia, Brasil. Biota Neotropica, Campinas, v. 9, n. 2, p. 131-138, 2009.

CAVALCANTE, A. L. A arte da pesca: análise socioeconômica da Reserva Extrativista de Canavieiras, Bahia. 2011. 108 f. Dissertação (Mestrado em Desenvolvimento Regional e Meio Ambiente) Universidade Estadual de Santa Cruz, Ilhéus. 2011.

CETRA, M.; PETRERE, M. Seasonal and annual cycles in marine small-scale fisheries (Ilhéus - Brazil). Fisheries Management and Ecology, East Yorkshire, v. 21, n. 3, p. 244-249, 2014.

COCKCROFT, V. G.; CLIFF, G.; ROSS, G. J. B. Shark predation on Indian Ocean bottlenose dolphins Tursiops truncatus off Natal, South Africa. South African Journal of Zoology, Pretoria, v. 24, n. 4 , p. 305-310, 1989.

COMPAGNO, L. J. V. Sharks of the world. An annotated and illustrated catalogue of shark species known to date. Part 2 Carcharhiniformes. Rome: Food and Agriculture Organization, $2001.655 \mathrm{p}$

COSTA, M. E.; LE PENDU, Y.; COSTA-NETO, E. M. Behaviour of Sotalia guianensis (van Bénéden, 1864) (Cetacea, Delphinidae) and ethnoecological knowledge of artisanal fishermen from Canavieiras, Bahia, Brazil. Journal of Ethnobiology and Ethnomedicine, London, v. 8, p. 18, 2012.

DÂMASO, R. C. S. C. Etnoecologia dos pescadores de Itacaré, BA. 2006. 95 f. Dissertação (Mestrado em Zoologia) - Universidade Estadual de Santa Cruz, Ilhéus. 2006.

DE LA PARRA VENEGAS, R.; HUETER, R.; GONZALEZ CANO, J.; TYMINSKI, J.; GREGORIO REMOLINA, J. An unprecedented aggregation of whale sharks, Rhincodon typus, in Mexican coastal waters of the Caribbean Sea. PLoS ONE, San Francisco, v. 6, n. 4, 2011.

DOVE, A. D. M. Foraging and ingestive behaviors of whale sharks, Rhincodon typus, in response to chemical stimulus cues. Biological Bulletin, Woods Hole, v. 228, p. 65-74, 2015.

DULVY, N. K.; HARISSON, L. R.; CARLSON, J. K.; DAVIDSON, L. N. K.; FORFHAM, S. V.; FRANCIS, M. P.; POLLOCK, C. M.; 
SIMPFENDORFER, C.A.; BURGESS, G. H.; CARPENTER, K. E.; COMPAGNO, L. J. V.; EBERT, D. A.; GIBSON, C.; HEUPEL, M. R.; LIVINGSTONE, S. R.; SANCIANGCO, J. C.; STEVENS, J. D.; VALENTI, S.; WHITE, W. T. Extinction risk and conservation of the world's sharks and rays. eLIFE, Cambridge, v. 3, e00590, 2014.

DUTRA, G. F.; ALLEN, G. R.; WERNER, T.; MCKENNA, S. A. A rapid marine biodiversity assessment of the Abrolhos Bank, Bahia, Brazil. RAP Bulletin of Biological Assessment 38. Washington, DC: Conservation International. 2006. 160 p.

ERLER, D. M.; LIMA JR., D. P.; SCHIAVETTI, A. Ecological fishing networks in a marine protected area: One possibility for evaluating objectives. Ocean \& Coastal Management, Augustinusga, v. 104, p. 106-114, 2015.

ESTES, J. A.; TERBORGH, J.; BRASHARES, J. S.; POWER, M. E.; BERGER, J.; BOND, W. J.; CARPENTER, S. R.; ESSINGTON, T. E.; HOLT, R. D.; JACKSON, J. B. C.; MARQUIS, R. J.; OKSANEN, L.; OKSANEN, T.; PAINE, R. T.; PIKITCH, E. K.; RIPPLE, W. J.; SANDIN, S. A.; SCHEFFER, M.; SCHOENER, T. W.; SHURIN, J. B.; SINCLAIR, A. R. E.; SOULÉ, M. E.; VIRTANEN, R.; WARDLE, D. A. Trophic downgrading of planet earth. Science, Washington, v. 333, p. 301-306, 2011.

FERRETTI, F.; WORM, B.; BRITTEN, G. L.; HEITHAUS, M. R.; LOTZE, H. K. Patterns and ecosystem consequences of shark declines in the ocean. Ecology Letters, Montpellier, v. 13, p. 10551071, 2010.

FIGUEIREDO, J. L. Manual de peixes marinhos do sudeste do Brasil. I. Introdução. Cações, raias e quimeras. São Paulo: Museu de Zoologia da Universidade de São Paulo. 1977. 104 p.

FRERE, E.; GANDINI, P.; LICHTSCHEIN, V. Variación latitudinal en la dieta del pinguino de Magallanes (Spheniscus magellanicus) em la costa patagónica, Argentina. Ornitologia Neotropical, Montreal, v. 7, p. 35-41, 1996.

GADIG, O. B. F. Fauna de tubarões da costa norte/nordeste do Brasil (Chondrichthyes, Elasmobranchii). 1994. $230 \mathrm{f}$. Dissertação (Mestrado em Ciências Biológicas) - Universidade Federal da Paraíba, João Pessoa. 1994.

HEITHAUS, M. R. The biology of tiger sharks, Galeocerdo cuvier, in Shark Bay, Western Australia: sex ratio, size distribution, diet, and seasonal changes in catch rates. Environmental Biology of Fishes, New York, v. 61, p. 25-36, 2001.

HEITHAUS, M. R.; FRID, A.; DILL, L. M. Species and sex-class differences in shark-inflicted injury frequencies, escape ability, and habitat use of green and loggerhead turtles. Marine Biology, Kiel, v. 140, p. 229-236, 2002.

HEITHAUS, M. R.; WIRSING, A. J.; THOMPSON, J.; BURKHOLDER, D. A review of lethal and non-lethal effects of predators on adult marine turtles. Journal of Experimental Marine Biology and Ecology, Amsterdam, v. 356, p. 43-51, 2008. HEUPEL, M. R.; SIMPFENDORFER, C. A. Science or slaughter: need for lethal sampling of sharks. Conservation Biology, San Francisco, v. 24, p. 1212-1218, 2010.

HEYMAN, W.; GRAHAM, R.; KJERFVE, B.; JOHANNES, R. Whale sharks Rhincodon typus aggregate to feed on fish spawn in Belize. Marine Ecology Progress Series, Oldendorf, v. 215, p. 275-282, 2001.
IBAMA. Monitoramento da atividade pesqueira no litoral nordestino-projeto ESTATPESCA. 2008. Disponível em: $<$ http:// www4.icmbio.gov.br/cepene/download.php?id_download=531>. Acesso em: 17 maio 2013.

JOHANNES, R. E.; FREEMAN, M. M.; HAMILTON, R. J. Ignore Fisher's knowledge and miss the boat. Fish and Fisheries, Vancouver, v. 1, n. 3, p. 257-271, 2000.

JOHNSON, R. L.; VENTER, A.; BESTER, M. N.; OOSTHUIZEN, W. H. Seabird predation by white shark, Carcharodon carcharias, and Cape fur seal, Arctocephalus pusillus pusillus, at Dyer Island. South African Journal of Wildlife Research, Pretoria, v. 36, n. 1, p. 00-00, 2006.

JONAHSON, M.; HARDING, S. Occurrence of whale sharks (Rhincodon typus) in Madagascar. Fisheries Research, St John's, v. 84, p. 132-135, 2007.

LOWE, C. G.; WeTherBeE, B. M.; CROW, G. L.; TESTER, A. L. Ontogenetic dietary shifts and feeding behavior of the tiger shark, Galeocerdo cuvier, in Hawaiian waters. Environmental Biology of Fishes, New York, v. 47, p. 203-211, 1996.

LUCIFORA, L. O.; GARCÍA, V. B.; WORM, B. Global diversity hotspots and conservation priorities for sharks. PLoSOne, Stanford, 6:e19356, 2011.

MACHADO, A. B. M.; DRUMMOD, G. M.; PAGLIA, A. P. Livro vermelho da fauna brasileira ameaçada de extinção. Brasília: Ministério do Meio Ambiente, 2008. 1420 p.

MÄDER, A.; SANDER, M.; CASA-JR, G. Ciclo sazonal de mortalidade do pingüim-de-magalhães, Spheniscus magellanicus influenciado por fatores antrópicos e climáticos na costa do Rio Grande do Sul, Brasil. Revista Brasileira de Ornitologia, Belém, v. 18, n. 3, p. 228-233, 2010.

MAGNUSON, J. The significance of sharks in human psychology. In: COOK, S. (Ed.). Sharks: an inquiry into biology, behavior, fisheries, and use. Oregon: Oregon State University Extension Service EM8330, 1987. p. 85-94.

MARQUES, J. G. W. Aspectos ecológicos na etnoictiologia dos pescadores do complexo estuarino-lagunar MundaúManguaba, Alagoas. 1991. 292 f. Tese (Doutorado em Ecologia) - Universidade Estadual de Campinas, Campinas. 1991.

MARQUES, J. G. W. Pescando pescadores. Ciência e etnociência em uma perspectiva ecológica. São Paulo: NUPAUB, 2001. 258 p.

MORAES, L. E.; ROMERO, R. M.; ROCHA, G. R. A.; MOURA, R. L. Demersal ichthyofauna of the inner continental shelf off Ilhéus, Bahia, Brazil. Biota Neotropica, Campinas, v. 9, p. $163-$ 168, 2009.

MOTTA, P. J.; WILGA, C. D. Advances in the study of feeding behaviors, mechanisms, and mechanics of sharks. Environmental Biology of Fishes, New York, v. 60, p. 131-156, 2001.

MYERS, R. A.; BAUM, J. K.; SHEPHERD, T. D.; POWERS, S. P.; PETERSON, C. H. Cascading effects of the loss of apex predatory sharks from a coastal ocean. Science, Washington, v. 315, n. 5820, p. 1846-1850, 2007.

NUNAN, G. W.; SENNA, M. L. V. Tubarões (Selachii) coletados pelo navio oceanográfico Thalassa sobre a plataforma externa e talude continental do Brasil entre $11^{\circ}$ e $22^{\circ}$ S. In: COSTA, P. A. S.; OLAVO, G.; MARTINS, A. S. (Ed.). Biodiversidade da fauna marinha profunda na costa central brasileira. Rio de Janeiro: Museu Nacional, 2007. p. 163-183. 
OLAVO, G.; COSTA, P. A. S.; MARTINS, A. S. Prospecção de grandes peixes pelágicos na região central da ZEE brasileira entre o Rio Real-BA e o Cabo de São Tomé-RJ. In: COSTA, P. A. S.; MARTINS, A. S.; OLAVO, G. (Ed.). Pesca e potenciais de exploração de recursos vivos na região central da Zona Econômica Exclusiva brasileira. Rio de Janeiro: Museu Nacional, 2005. p. 167-202.

QUEIROZ, E. L.; REBOUÇAS, S. C. Tubarão - Quem tu és? Salvador: Laboratório de Nectologia/EDUFBA, 1995. 76 p.

RICKLEFS, R. E. A economia da natureza. Rio de Janeiro: Editora Guanabara Koogan, 2003. 503 p.

SIMPFENDORFER, C. A.; WETHERBEE, B. Shark and ray life history. Marine and Freshwater Research, Collingwood, v. 66, p. i-ii, 2015.

STACEY, N. E.; KARAM, J.; MEEKAN, M. G.; PICKERING, S.; NINEF, J. Prospects for whale shark conservation in Eastern Indonesia through Bajo traditional ecological knowledge and community-based monitoring. Conservation and Society, Bangalore, v. 10, p. 63-75, 2012.

STEVENS, J. D., BONFIL, R.; DULVY, N. K.; WALKER, P. A. The effects of fishing on sharks, rays, and chimaeras (chondrichthyans), and the implications for marine ecosystem. ICES Journal of Marine Science, Copenhagen, v. 57, p. 476-494, 2000.
SZPILMAN, M. Tubarões no Brasil: guia prático de identificação. Rio de Janeiro: Aqualittera, 2004. 160 p.

VASCONCELlOS, M.; DIEGUES, A. C.; KALIKOSKI, D. C. Coastal fisheries of Brazil. In: SALAS, S.; CHUENPAGDEE, R.; CHARLES, A.; SEIJO, J. C. (Ed.). Coastal fisheries of Latin America and the Caribbean. Rome: FAO Fisheries and Aquaculture Technical Paper, 2011. p. 73-116.

VASQUES, R. O. Dinâmica populacional do camarão rosa Farfantepenaeus paulensis Pérez-Farfante, 1967), Crustacea, Decapoda, e caracterização da pesca camaroneira na zona norte de Ilhéus. 2006. 149 f. Dissertação (Mestrado em Zoologia) - Universidade Estadual de Santa Cruz, Ilhéus. 2006.

WILGA C. D.; MOTTA P. J.; SANFORD, C. P. Evolution and ecology of feeding in elasmobranchs. Integrative and Comparative Biology, Oxford, v. 47, p. 55-69, 2007.

ZERBINI, A. N.; ANDRIOLO, A.; DA ROCHA, J. M.; SIMÕESLOPES, P. C.; SICILIANO, S.; PIZZORNO, J. L.; WAITE, J. M.; DEMASTER, D. P.; VANBLARICOM, G. R. Winter distribution and abundance of humpback whales (Megaptera novaeangliae) off Northeastern Brazil. Journal of Cetacean Research and Management, Cambridge, v. 6, p. 101-107, 2004. 